\title{
PERANCANGAN APLIKASI INVENTARIS BARANG BERBASIS WEB DENGAN PENGUJIAN MENGGUNAKAN PEMODELAN NIELSEN
}

\author{
M. Rudi Sanjaya ${ }^{1 *}$, Jaidan Jauhari ${ }^{2}$, Dedy Kurniawan ${ }^{3}$ \\ 1*Laboratorium Pemrograman Internet Fakultas Ilmu Komputer Universitas Sriwijaya \\ email : m.rudi.sjy@ilkom.unsri.ac.id \\ ${ }^{2}$ Laboratorium Instrumentasi dan Aplikasi Nanoteknologi Fakultas Ilmu Komputer Universitas Sriwijaya \\ email : jaidan_j@yahoo.com \\ ${ }^{3}$ Laboratorium Pemrograman Lanjut Fakultas Ilmu Komputer Universitas Sriwijaya \\ email : dedykurniawan@unsri.ac.id
}

\begin{abstract}
The development of technology is increasingly fast and developing, so the need for a technology is one of the webs-based software technology, with this web being used to make difficult work easy, the purpose of this research is to design and build an inventory application for Islamic boarding schools Miftahul Jannad. in the survey village by applying the Nielsen modeling. The research method used is the method of observation, interviews and literature studies, the approach method is the Nielsen modeling method, where Nielsen's modeling consists of learnability, efficiency, memorability, few errors, satisfaction, the results of Nielsen's modeling are obtained to test the validity of learnability with counted $r$ counts. $0.868,0.845$, $0.736,0.619$, Efficiency with $r$ count $0.813,0.461 .0 .636$, 0.557, for Memorability is 0.773, 0.830, 0.814, 0.578 for memorability with the calculated $r$ value of $0.773,0.830,0.814,0.578$, then for few errors obtained a value of $0.621,0.765,0.704,0.653$, then for satisfaction with a value of $0.732,0.559,0.662$, 0.652 , which means that with the calculated $r$ value is more $r$ table, where the r table is obtained 0.320, the data in the Nielsen modeling is valid, while for the reliability test it is stated that the results of the Nielsen modeling test are reliable.
\end{abstract}

Keywords : learnability, efficiency, memorability, few errors, satisfaction

\section{PENDAHULUAN}

Kota palembang merupakan provinsi Sumsel (Sumtera Selatan) kota sudah berkembang dari zaman ke zaman sehingga kota Palembang di sebut dengan kota metropolitan. Provinsi Sumatera Selatan mempunyai banyaknya kabupaten, kecamatan dan desa, salah satunya adalah desa Peninjauan dengan nama Kecamatan Peninjauan. Desa peninjauan adalah desa yg belum berkembang dalam penggunaan perkembangan teknologi salah satu adalah teknologi perangkat lunak atau aplikasi. Selain itu, juga kesulitan untuk mengembangkan teknologi, salah satunya di Pondok Pesantren Miftahul Jannah, dimana pesantren tersebut memiliki visi dan misi untuk menjadi siswa atau santri dan santriwati menjadi akhlak mulia, penghafal alqur'an, menyampaikan dakwah untuk umat islam.

Saat ini pendataan barang inventaris pada
Pondok Pesantren Miftahul Jannah belum menggunakan teknologi. Menurut observasi langsung kepala Sekolah Madrasah Aliyah yang bernama Rosnadiyah, M.Pd. bahwa di sekolah atau di pondok pesantren ini belum ada perangkat lunak yaitu perangkat lunak untuk menyimpan data yaitu inventaris barang sekolah khususnnya di Pondok Pesantren Miftahul Jannah Desa Peninjauan berbasis web.

Untuk pengembangan pesantren tersebut maka dimanfaatkan pengembangan teknologi yakni dengan merancang aplikasi pendataan inventaris barang dengan berbasis web. Melalui web penyampaian informasi-informasi menjadi lebih mudah, cepat, akurat dan terpecaya [1]. Penggunaan teknologi dalam pendataan barang inventaris kini telah digunakan diberbagai tempat, antara lain: Sistem atau Aplikasi inventaris barang berbasis web di sekolah tinggi teknologi terletak di Garut dimana aplikasi web 
ini dirancang dengan memiliki rule atau aturan yang bisa untuk membuat laporan mengenai data barang dan juga transaksi yang terjadi dalam proses pengelolaan data-data inventaris secara otomatis dengan tujuan untuk mempermudah dalam pembuatan laporan. Kemudian Aplikasi inventaris barang dirancang memiliki fitur-fitur multi pengguna atau user yang bisa mendapatkan informasi mengenai inventaris barang dengan mudah yang dibedakan sesuai dengan tipe masing-masing user [2]. Sistem inventaris di rancang untuk bisa membantu dalam kinerja petugas tata usaha untuk menyelesaikan pendataan asset barang sehingga di harapkan lebih efisien dan lebih menghemat waktu [3], [4]. SMA N 1 Dumai merangcang sebuah Sistem Informasi Inventaris Barang dengan Menggunakan untuk memberi sebuah solusi kemudahan dalam mendata barang [5]. Adapun kriteria perancangan desaian yan baik adalah website yang responsive, desain mudah digunakan atau simple, speed website yang cepat dan juga berisi konten yang menarik dan relevan [6].

Oleh karena itu dirancang sebuah aplikasi pendataan inventaris barang berbasis web untuk mempermudah pengelolaan data inventaris barang, sehingga inventaris barang tersimpan dalam sebuah database, dan aplikasi tersebut dirancang dengan menggunakan pemodelan Nilsen. Web ini dirancang menggunakan Bahasa-bahasa pemrograman salah satu misalnya Bahasa pemrograman PHP, java script, sehingga tampilan dalam web tersebut memilik tampilan yang indah dan juga isi informasinya mudah di akses [7].

\section{METODE PENELITIAN}

Adapun tahapan penelitian yang dilakukan dimulai dari perancangan aplikasi ber basis web dan selanjutnya digunakan pemodelan Nielsen untuk mengetahui tingkat kepuasan dalam membuat aplikasi, Adapun kriterian pemodelan Nielsen terdiri dari learnability, efficiency, memorability, few errors, satisfaction [8].

Metode pengembangan perangkat lunak dalam penelitian ini menggunakan metode Prototype [9]. Adapun tahapan dalam metode Prototype ini adalah sebagai berikut [10]:

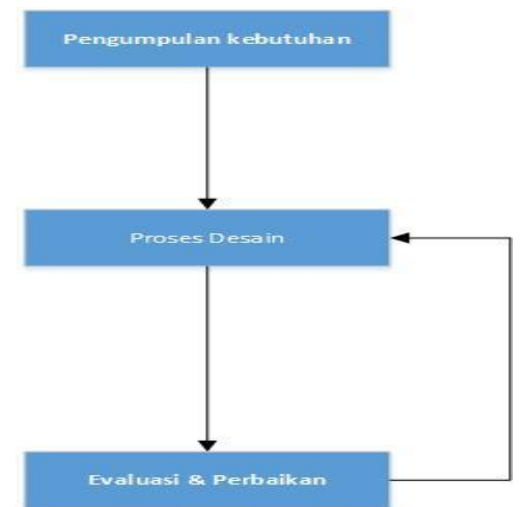

Gambar 2. Metode Pengembangan Perangkat Lunak

Tahap pertama untuk membangun perangkat lunak ini adalah mengumpulkan kebutuhan, yang dilakukan melalui hasil observasi, wawancara, mengindentifikasi kebutuhan secara bersama-sama, kemudian membuat batasan perangkat lunak yang dibangun. Selanjutnya dibangun prototype atau di kenal dengan Build prototype sesuai dengan apa yang diinginkan oleh sekolah. Kemudian tahap selanjutnya dilakukan proses desain sesuai kebutuhan, dan selanjutnya membuat program Bahasa pemrograman PHP [11].

Rancangan perangkat lunak terbagi dua aktor yaitu sebagai wakil sarana dan prasarana dan kepala sekolah seperti pada gambar 3 .

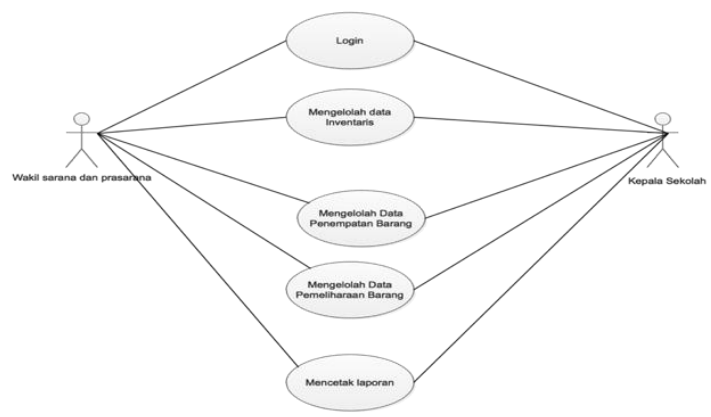

Gambar 3. Use case diagram

Tahapan selanjutnya adalah testing, yaitu menguji perangkat ini apakah sesuai dengan keinginan pengguna atau tidak, pengujian 
menggunakan pemodelan Nielsen [12].

Pemodelan Nielsen dinyatakan dalam bentuk usability yang terdiri dari lima dapat dilihat gambar di bawah ini [9] :

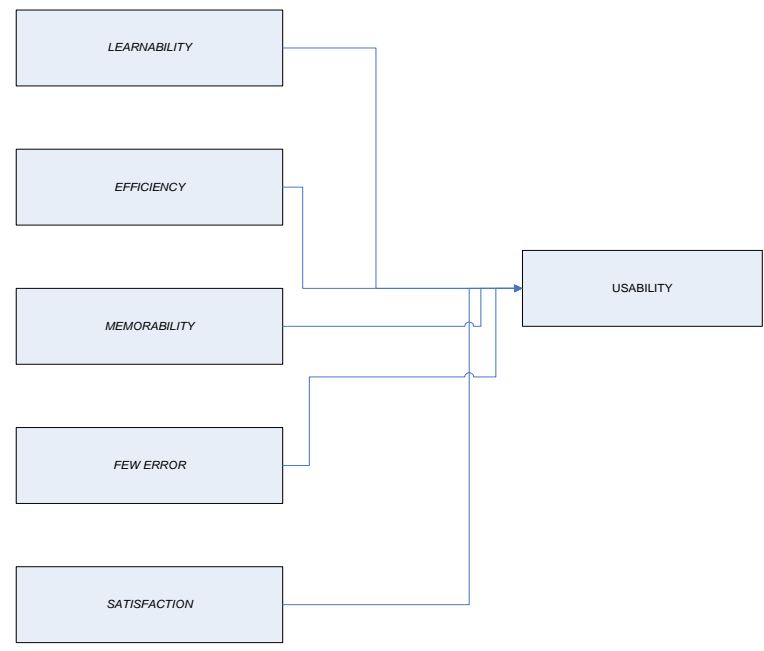

Gambar 1. Pemodelan Nielsen

Adapun penjelasan pada gambar di atas adalah [13]:

1) Learnability artinya pengguna mudah mempelajari perangkat lunak yang akan di bangun

2) Efficiency artinya perangkat lunak ini mudah digunakan oleh user atau pengguna

3) Memorability artinya perangkat lunak mudah di inggat oleh pengguna

4) Few Error artinya Perangkat lunak sudah di tes untuk menghindari terjadi kesalahan.

5) Satisfaction artinya perangkat lunak ini telah di bangun dan digunakan oleh user sehingga pengguna atau user merasa puas dengan kinerja perangkat lunak yang di bangun.

\section{HASIL DAN PEMBAHASAN}

\subsection{Hasil Perancangan Aplikasi Web}

Adapun hasil perancangan dari aplikasi inventaris barang berbasis web pada Pondok pesantren miftahl Jannah terdiri dari :

\section{Halaman Login}

Kepala sekolah dan wakil sarana dan prasarana melakukan login, Ketika login sudah berhasil maka akan masuk, Adapun tampilan login dapat dilihat pada gambar 6 di bawah ini :

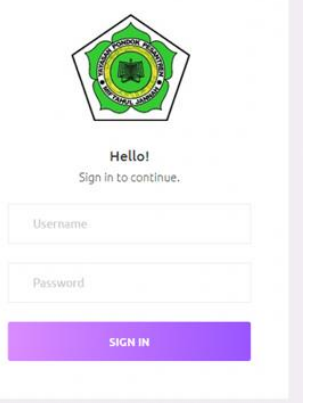

Gambar 4. Halaman Login

\section{Halaman Dashboard}

Pada tampilan halaman dashboard dapat dilihat gambar 5 dibawah ini :
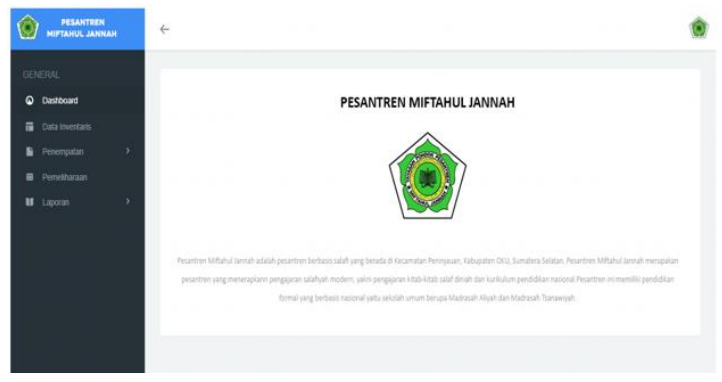

Gambar 5. Halaman Dashboard

Pada gambar 5 adalah halaman dashboard yang berisi tentang visi dan misi pondok pesantren miftahul Jannah di desa peninjauan

\section{Halaman Data Inventaris}

Adapun halaman data inventaris barang tampilannya pada gambar 6 di bawah ini

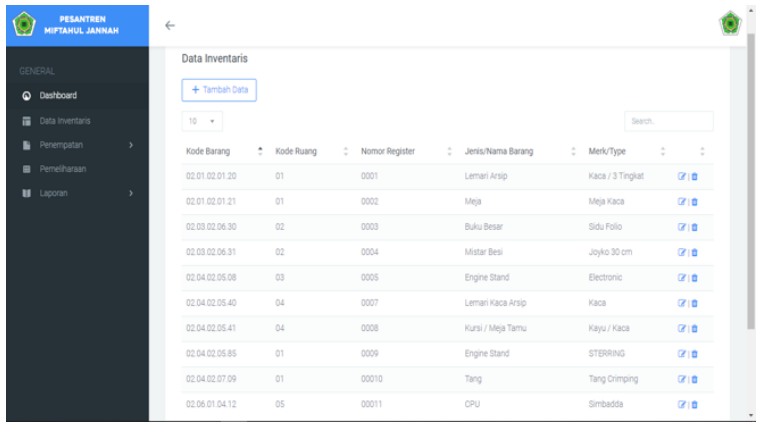

Gambar 6. Halaman Data Inventaris

Pada gambar 6 menjelaskan data-data inventaris telah di inputkan yang terdiri kode barang, kode 
ruang, nomor register jenis atau nama barang, dan jiga merek dan type, dan juga dapat melakukan edit dan hapus

4. Halaman Data Barang

Adapun tampilan halaman data barang tampilan di bawah ini :
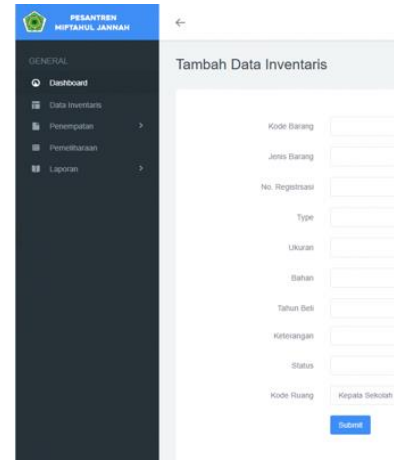

\section{Gambar 7. Halaman Data Barang}

Pada gambar di atas yaitu untuk menambah data inventaris barang yang terdiri dari kode barang, jenis barang, no registrasi, type, ukuran barang, bahan, tahun beli barang, status barang, dan kode ruang barang kemudian di submit.

5. Halaman Penempatan Ruang Kepala Sekolah Adapun tampilan halaman penempatan ruang kepala sekolah dibawah ini :
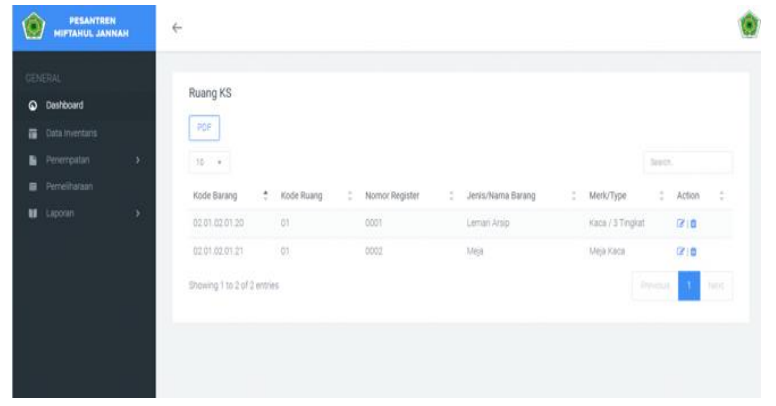

Gambar 8. Halaman Penempatan Ruang Kepala

Sekolah, Pada gambar 8 menjelaskan tampilan deng menu penempatan barang, dimana halaman ini untuk menampilkan data barang yang ada di ruang kepala sekolah.

\section{Halaman Penempatan Ruang AK}

Adapun tampilan halaman ruang AK dapat dilihat pada gambar 9 :
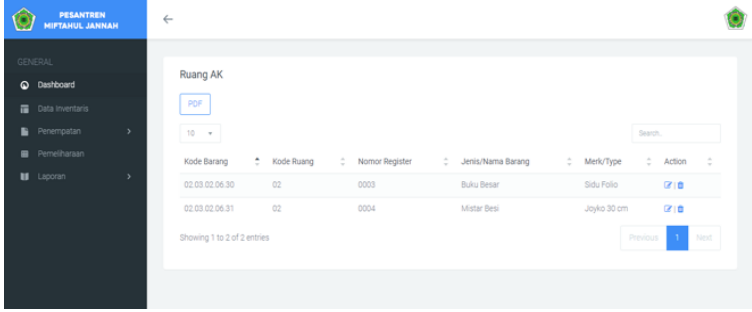

Gambar 9. Halaman Penempatan Ruang AK

Gambar 9 meripakan tampilan menu penempatan barang. Halaman ini untuk menampilkan data di ruang AK yang terdiri dari kode barang, kode ruang, nomor register, jenis atau nama barang dan juga merek atau type

\section{Halaman Penempatan Ruang Tamu}

Adapun tampilan halaman penempatan ruang tamu dapat dilihat gambar 10 :

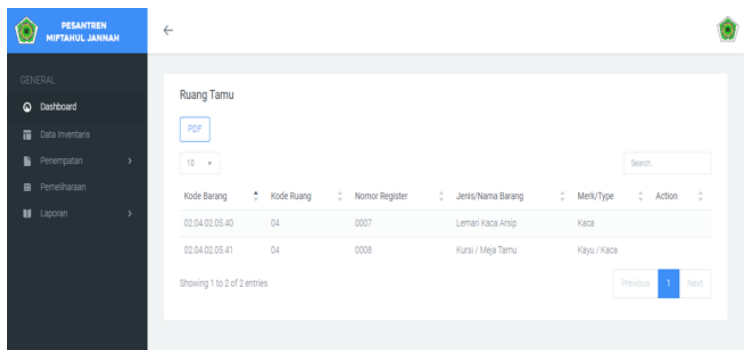

Gambar 10. Halaman Penempatan Ruang Tamu

Pada gambar 10 menjelaskan tampilan dari halaman menu penempatan ruang tamu, dimana halaman ini untuk menampilkan data yang ada di ruang Tamu saja, yang terdiri dari kode barang, kode ruang, nomor register, jenis atau nama barang, merek atau type.

\section{Halaman Penempatan Ruang TU}

Adapun untuk halaman penempatan ruang TU adalah sebagai berikut :
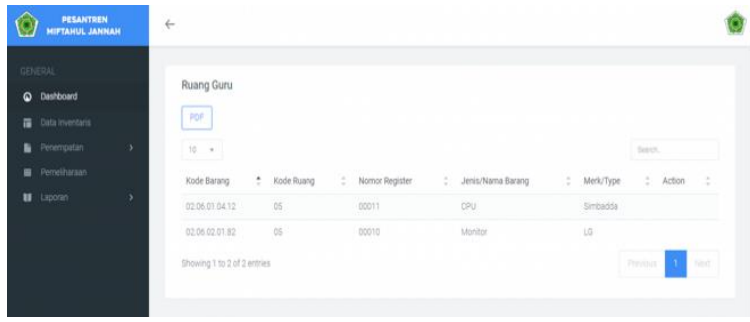

Gambar 11. Halaman Penempatan Ruang TU 
Pada gambar 11 menjelaskan dari tampilan dari menu penempatan ruang TU. Di Halaman ini hanya untuk menampilkan data yang ada atau berada di ruang TU saja yang terdiri dari kode barang, kode ruang, nomor register, jenis atau nama barang, merek atau type.

9. Halaman Penempatan Ruang TBSM Tampilan halaman penempatan Ruang TBSM adalah sebagai berikut :
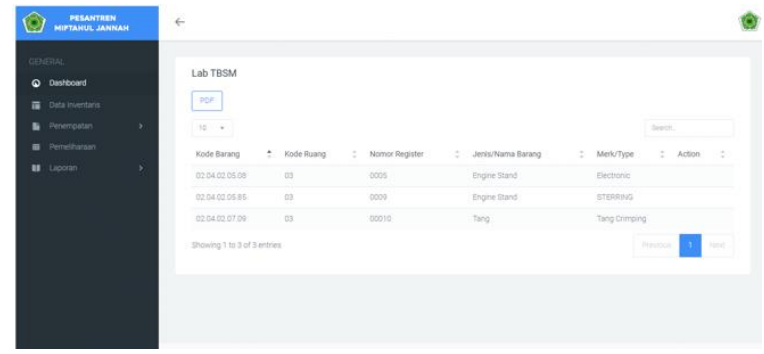

Gambar 12. Halaman Penempatan Ruang TU

Pada gambar 12 adalah tampilan dari menu penempatan ruang TBSM dimana Halaman ini hanya untuk menampilkan data yang berada di ruang TBSM saja, yang terdiri dari kode barang, kode ruang, nomor register, jenis atau nama barang, merek atau type.

10. Halaman Tambah Data Pemeliharaan

Adapun tampilan halaman tambah data pemeliharaan dapat dilihat pada gambar 13 .

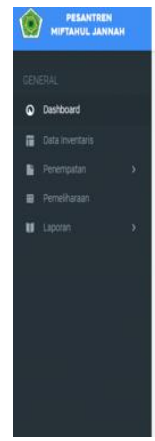

Tambah Data Pemeliharaan

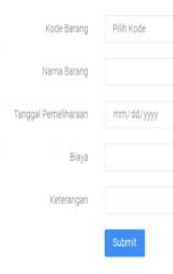

Gambar 13. Halaman Tambah Data Pemeliharaan

Pada gambar 13 ini menjelaskan tampilan menu tambah data untuk pemeliharaan barang, pada halaman ini juga digunakan pengguna untuk memasukan data barang yang akan di pelihara atau maintenace yang nantinya akan tampil pada halaman data pemeliharaan barang
11. Halaman Pemeliharaan

Tampilan halaman pemeliharaan dapat dilihat gambar 14 :

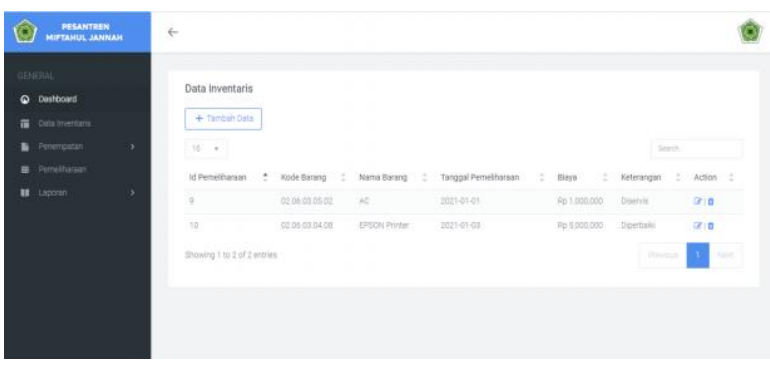

Gambar 14. Halaman Pemeliharaan

Pada gambar 14 adalah halaman untuk menampilkan data barang yang akan di pelihara atau di maintenace Adapun tujuan barang ini untuk mengetahui agar barang tersebut tetap dalam keadaan baik dan siap diguanakan.

\section{Menu Laporan Inventaris}

Adapun tampilan menu laporan data inventaris barang adalah dapat dilihat pada gambar 15 .

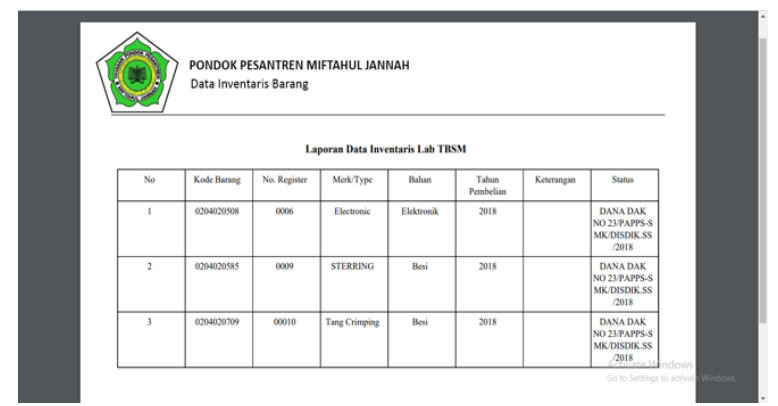

Gambar 15. Menu Laporan Inventaris Barang

Pada gambar 15 merupakan tampilan dari laporan penempatan barang dimana data sesuai dengan ruang, misalnya di data inventaris lab TBMS di Pondok Pesantren Miftahul Jannah.

\subsection{Pengujian dengan Menggunakan Pemodelan Nilesen}

Pemodelan Nielsen dilakukan dengan menggunakan SPSS versi 25, dengan menggunakan data dari 40 responden yaitu guru madrasyah Aliyah dan Madrasah (MA) Tsaniwiya (MTS). 


\subsection{Hasil pengelolahan data pemodelan Nielsen Uji validitas}

Adapun hasil uji validitas dapat dilihat gambar 16 dibawah ini :

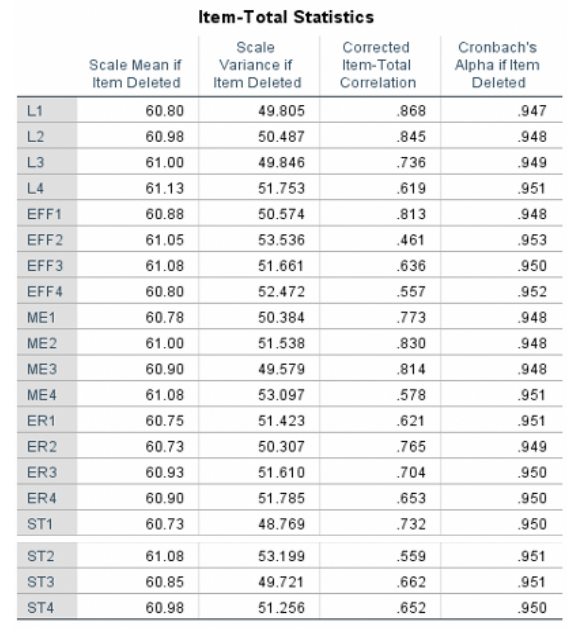

Gambar 16. Uji validitas Pemodelan Nielsen

Pada gambar 16 dapat dilihat hasil corrected item-total dimana rhitung > rtabel, maka dapat secara spesifik pada tabel 1 dibawah ini :

Tabel 2. Perbandingan $r$ hitung dan $r$ tabel

\begin{tabular}{llll}
\hline Variabel & r hitung & r tabel & Keterangan \\
\hline LI & 0,868 & 0.320 & Valid \\
L2 & 0,845 & 0.320 & Valid \\
L3 & 0,736 & 0.320 & Valid \\
L4 & 0,619 & 0.320 & Valid \\
EFF1 & 0,813 & 0.320 & Valid \\
EFF2 & 0,461 & 0.320 & Valid \\
EFF3 & 0,636 & 0.320 & Valid \\
EFF4 & 0,557 & 0.320 & Valid \\
ME1 & 0,773 & 0.320 & Valid \\
ME2 & 0,830 & 0.320 & Valid \\
ME3 & 0,814 & 0.320 & Valid \\
ME4 & 0,578 & 0.320 & Valid \\
ER1 & 0,621 & 0.320 & Valid \\
ER2 & 0,765 & 0.320 & Valid \\
ER3 & 0,704 & 0.320 & Valid \\
ER4 & 0,653 & 0.320 & Valid \\
ST1 & 0,732 & 0.320 & Valid \\
ST2 & 0,559 & 0.320 & Valid \\
ST3 & 0,662 & 0.320 & Valid \\
ST4 & 0,652 & 0.320 & Valid \\
\hline
\end{tabular}

Pada Tabel 2 perbandingan $r$ hitung dan $r$ tabel dengan responden sebanyak 40 untuk Learnability, efficiency, memorability, Few error, dan statisfaction menyatatakan data di atas valid

\subsection{Hasil pengelolahan data pemodelan Nielsen Uji realibiltas}

Pada tabel 3 ini menguji pemodelan Nielsen dengan menggunakan uji realibilitas dapat dilihat dibawah ini

Tabel 3. Pemodelan Nielsen Uji Realibiltas

\begin{tabular}{cccc}
\hline Variabel & r hitung & r tabel & Keterangan \\
\hline LI & 0,947 & 0.70 & Reliabel \\
L2 & 0,948 & 0.70 & Reliabel \\
L3 & 0,949 & 0.70 & Reliabel \\
L4 & 0,951 & 0.70 & Reliabel \\
EFF1 & 0,948 & 0.70 & Reliabel \\
EFF2 & 0,953 & 0.70 & Reliabel \\
EFF3 & 0,950 & 0.70 & Reliabel \\
EFF4 & 0,952 & 0.70 & Reliabel \\
ME1 & 0,948 & 0.70 & Reliabel \\
ME2 & 0,948 & 0.70 & Reliabel \\
ME3 & 0,948 & 0.70 & Reliabel \\
ME4 & 0,951 & 0.70 & Reliabel \\
ER1 & 0,951 & 0.70 & Reliabel \\
ER2 & 0,949 & 0.70 & Reliabel \\
ER3 & 0,950 & 0.70 & Reliabel \\
ER4 & 0,950 & 0.70 & Reliabel \\
ST1 & 0,950 & 0.70 & Reliabel \\
ST2 & 0,951 & 0.70 & Reliabel \\
ST3 & 0,951 & 0.70 & Reliabel \\
ST4 & 0,950 & 0.70 & Reliabel \\
\hline
\end{tabular}

Pada tabel 3 menggunakan uji realibilitas dimana syaratnya adalah jika nilai alpha lebih besar dengan $r$ tabel maka data tersebut menyatakan realibilitas, dapat dilihat gambar di atas bahwa data di atas lebih besar $r$ tabel di mana r tabelnya adalah 0,70 maka di nyatakan data tersebut Reliabel.

\section{KESIMPULAN}

Perangkat lunak ini berbasis web di rancang dan juga bangun menggunakan kriteria yaitu pemodelan Nielsen, Adapun hasil dari penelitian yang terdiri learnability, efficiency, memorability, few errors, satisfaction, hasil 
pemodelan Nielsen didapatkan untuk uji validitas learnability dangan nilar $\mathrm{r}$ hitung $0,868,0,845$, $0,736,0,619$, Efficiency dengan nilai $r$ hitung 0,813, 0,461,0,636, 0,557, untuk Memorability adalah $0,773, \quad 0,830, \quad 0,814, \quad 0,578$ untuk memorability dengan nilai $\mathrm{r}$ hitung adalah 0,773 , $0,830,0,814,0,578$, kemudian untuk few error didapatkan nilai $0,621,0,765,0,704,0,653$, selanjutanya untuk satisfaction dengan nilai $0,732,0,559,0,662,0,652$ artinya dengan nilai $r$ hitung lebih $r$ tabel, dimana $r$ tabel di dapatkan 0,320 maka data dalam pemodelan Nielsen tersebut valid, sedangkan untuk uji realibilitas itu dinyatakan hasil pengujian pemodelan Nielsen adalah reliabel, dapat dinyatakan bahwa web ini sudah di uji dengan menerapkan metode Pemodelan Nielsen.

\section{REFERENSI}

[1] A. M. T. Nugraha, A. Y. Saputra, dan R. S. Dewi, "Software Development Website Inventaris Pada Pusat Perbelanjaan XYZ," JURIKOM (Jurnal Ris. Komputer), vol. 7, no. 1, 2020, doi: 10.30865/jurikom.v7i1.1862.

[2] Ridwan Setiawan, A. Ikhwana, dan E. Rahayu, "Pengembangan Aplikasi Pengelolaan Inventaris Barang Berbasis Web Di Sekolah Tinggi Teknologi Garut," J. Algoritm., vol. 14, no. 2, 2017.

[3] M. N. Witama, "Perancangan Aplikasi Pengelolaan Aset Barang Inventaris SDN Makasar 05 Pagi Jakarta Timur," STRING (Satuan Tulisan Ris. dan Inov. Teknol., vol. 3, no. 3, 2019, doi: 10.30998/string.v3i3.3578.

[4] A. Akhmadipura, "Darul Ma ' Arif Pamanukan Perancangan Sistem Informasi Inventaris Pada Smk Darul Ma 'Arif Pamanukan," Darul Ma 'Arif Pamanukan Peranc. Sist. Inf. Inventar. Pada Smk Darul Ma'Arif Pamanukan, vol. 1, 2018.

[5] A. Sofiyan, S. Sularno, dan F. Yuliana, "SISTEM INFORMASI INVENTARIS BARANG MENGGUNAKAN BAHASA PEMROGRAMAN PHP PADA SMAN 1 DUMAI," I N F O R M A T I K A, vol. 11, no. 1, 2019, doi: 10.36723/juri.v11i1.155. "PERANCANGAN APLIKASI WEB BERBASIS USABILITY," J. Tek. Inform., vol. 12, no. 1, 2017, doi: 10.35793/jti.12.1.2017.17856.

[7] C. Ramita, I. Ariyanti, dan L. Novianti, "Aplikasi monitoring dan pengaduan inventaris barang pada jurusan manajemen informatika berbasis website," JASISFO (Jurnal Sist. Informasi), vol. 1, no. 2, 2020.

[8] D. Salah, R. Paige, dan P. Cairns, "Integrating agile development processes and user centred design - a place for usability maturity models?," Lect. Notes Comput. Sci. (including Subser. Lect. Notes Artif. Intell. Lect. Notes Bioinformatics), vol. 8742, 2014, doi: 10.1007/978-3-662-44811-3_7.

[9] M. R. Sanjaya, "REKAYASA MODEL PERANGKAT LUNAK GEOGRAFIS PARIWISATA UNTUK PENCARIAN WISATA TEMPAT UMUM DAN TEMPAT TRANSPORTASI KOTA PALEMBANG," J. Digit. Teknol. Inf., vol. 1, no. 1, 2018, doi: 10.32502/digital.v1i1.931.

[10] T. Pricillia dan Zulfachmi, "Perbandingan Metode Pengembangan Perangkat Lunak (Waterfall, Prototype, RAD)," J. Bangkit Indones., vol. 10, no. 1, 2021, doi: 10.52771/bangkitindonesia.v10i1.153.

[11] J. Santoso, "Usability User Interface dan User Experience Media Pembelajaran Kamus Kolok Bengkala Berbasis Android," J. Sist. Dan Inform., 2018.

[12] M. R. Sanjaya, D. Kurniawan, dan A. Saputra, "GIS Android mobile based Software Development for Tourism Objects, Public Places list, Transportations list, and Culinary Places list Using Usability Measurement," 2020, doi: 10.1088/1742-6596/1500/1/012117.

[13] F. Giese dan T. Konstandin, "Vacuum stability of Froggatt-Nielsen models," $J$. High Energy Phys., vol. 2019, no. 12, 2019, doi: 10.1007/JHEP12(2019)091. 